\title{
Socio-Economic Profile of Farmers in Sericulture Based Dairy Farming System in Karnataka State, India
}

\author{
C. E. Girish, K. S. Kadian, B. S. Meena and Kalyan Mandi* \\ Dairy Extension Division, National Dairy Research Institute, Karnal, Haryana 132001 India \\ *Corresponding author
}

\begin{abstract}
A B S T R A C T
This paper describes socio-economic profile of farmers practicing sericulture based dairy farming system in Karnataka state. The study was therefore, conducted in the Karnataka state as it is the highest producer of silk in the country and is also ranked $11^{\text {th }}$ among top milk producing state in India. Two districts were selected for the purpose of study (Kolar and Chikkaballapura). From each district two blocks was randomly selected. And, from each block three villages were randomly selected, wherein 15 respondents were randomly selected from each village. Therefore, a total of 180 respondents were selected for the study. The major findings of the study revealed that, around 64.44 per cent of respondents belonged to middle age group and about 35.00 per cent of the respondents were educated up to primary school level. Around 47.77 per cent of respondents were maintaining herd size of 4 to 6 animals; majority $(54.44 \%)$ of the respondents belonged to low level of experience in dairying and sericulture, around 53.88 per cent of the farmers fell in medium category of milk production. In social participation, majority of the respondents had low participation which was about 60.00 per cent. With respect to extension contact, majority $(50.55 \%)$ of the respondents belonged to low level of contact with extension personnel. And, mass media exposure enunciated that maximum number of respondents belonged to maximum level $(59.44 \%)$ of exposure to mass media.
\end{abstract}

\section{Keywords}

Socio, Economic, Sericulture, Dairy, Farmers

\section{Article Info}

Accepted:

15 March 2020

Available Online:

10 April 2020

\section{Introduction}

India is the 'Oyster' of the global dairy industry with opportunities galore for the entrepreneurs globally. Since last 15 years, India continues to be the largest producer of milk in the world. Milk is one of the major outputs of dairy sector and most of the milk in the country is being produced by small and marginal farmers coupled with landless labourers. India attained the status of world's largest milk producing nation with an annual production of 187.7 million tonnes and subsequently the per capita availability of milk hovers around 394 g/day (NDDB, 201819). The annual growth rate in milk has been estimated at 6.50 per cent and the nation holds a share of 21 per cent in global milk production (DAHD\&F, 2018-19). Dairy sector is the most important sub-sector of 
livestock, milk group accounts for 67 per cent of the value of output from livestock sector. The per capita monthly expenditure on milk and milk products is increasing both in rural (₹ 116.38) and urban areas (₹ 187.14) (NSSO, 2012). Also with respect to Sericulture scenario of the country, India is the second largest producer of silk in the world. Among the four varieties of silk produced in 2015-16, Mulberry accounted for 71.8 per cent $(20,434$ MT) of the total raw silk production of 28,472 MT (CSB, 2016).

The demand for superior quality bi-voltine silk is increasing in India for domestic consumption as well as value added silk products for the export market. The Ministry of Textiles Government of India and Departments of Sericulture in various states provide technical and financial assistance for enhancing the bi-voltine silk production. Sericulture is an agro-based, labour intensive, export oriented commercial activity. It is an important cottage industry in Karnataka. Sericulture which was considered as a subsidiary occupation in the past is being considered as major activity.

Traditional farming system used by farmers in India are based on centuries of experiences characterized by mixed farming involving crop production with one or more enterprises like dairy, sericulture, poultry, piggery, sheep, goat, fisheries and bee-keeping. Their main aims were to achieve stability of production, provide subsistence for the family and guard against weather aberration and other environmental stresses. Dairy enterprise is one of the important activities which can suit the performance of sericulture.

As it is very well known that the combination of enterprises 'silk and milk' is very popular venture in Kolar and Chikkaballapura district of Karnataka. Many studies have also revealed this fact as true from the sense of effective enterprise combination. The farmers in the district are known to be highly innovative and the routine agricultural crops are combined inter alia with allied enterprises such as vegetables, dairy, sericulture, poultry and piggery. Earlier studies revealed that when dairy enterprise was combined with other enterprises on scientific lines offered greater opportunities for increasing farm income and employment, particularly to the weaker sections of the rural community (Komala, 2002).

Therefore, sericulture and dairy farming play synergistic role in the livelihood of farmers particularly in Karnataka state. It provides assured income and employment to the farmers. Keeping this in view, the study was conducted to explore the socio-economic profile of farmers practicing sericulture based dairy farming in Karnataka state.

\section{Materials and Methods}

The study was undertaken in the Karnataka state during the year 2017-18. The said state was purposively selected as Karnataka being the highest producer of silk in the country and was ranked $11^{\text {th }}$ among milk producing states in India. Two districts were selected for the purpose of study (Kolar and Chikkaballapura). From each districts two blocks were randomly selected. And, from each block three villages were randomly selected, wherein 15 respondents were randomly selected from each village.

Therefore, a total of 180 respondents were selected for the study. The semi-structured interview schedule was developed and purposively used. A total of 11 socioeconomic indicators selected to access the socio-economic profile of the respondents; here Age is operationalized as number of years completed by the respondents. Education is operationalized as the level of 
formal education accomplished by an individual respondent at the time of investigation. Family size was defined as total number of family members that depends on the head of the family. Land holding is defined as the total number of hectares of land owned and leased in by the individual family to operate the farming system. Experience in dairying and sericulture is interpreted as number of completed years by the respondent in dairy and sericulture farming.

Herd size was operationalized as the dairy animal wealth possessed by the respondent. Annual income was operationally defined as the income generated from various sources in one year by the respondent at the time of enquiry. Milk production was operationally defined as the quantity of milk produced in litres by all milch animals in litres/day. Social participation was operationally defined as extent of participation of a respondent in number of social organizations.

Extension contact was operationalized as the degree to which an individual maintains contact with the formal organizations, extension agency and government officials in a specified period of time. Mass media participation refers to the degree to which a respondent was exposed to different mass media such as newspaper, radio and television etc. The respondents were classified into small, medium and large category based on mean, range and standard deviation. The statistical tools used for the analysis of the results were indicated in frequency and percentages.

\section{Results and Discussion}

The result obtained from the study revealed the Socio-Economic profile of farmers adopting sericulture based dairy farming in the selected districts of Karnataka State. To access the socio-economic profile different variables were selected viz. age, education, family size, land holding, herd size, experience in dairying and sericulture, annual income, milk production, social participation, extension contact and mass media exposure.

\section{Age}

It was observed that 64.44 per cent of respondents belonged to middle age group; old aged group occupies 21.67 per cent of the respondents and followed by 13.89 per cent young aged group in Table 1. On overall basis majority of the farming community belonged to the middle to old aged group. This might be due to youths are more attracted towards non-farm jobs as well as emigration. The above results are in line with the findings of Khin Mar Oo (2005), Mande and Thombre (2009), Kumar (2009) and Nataraju (2012).

\section{Education}

A close look on Table 1 revealed that 35.00 per cent of the respondents were educated up to primary school level followed by 19.44 per cent educated up to middle school. However, 15.00 per cent respondents were illiterate in the study area of Kolar and Chikkaballapur. It was noticed that marginal farmer were slightly more illiterate as compared to other farmers. Because of low income in this category of farmers, they could not access higher education. Rest all were having medium to high education level. The findings of Wadear et al., (2003), Chauhan et al., (2004), Khin Mar Oo (2005), Arora et al., (2006), Mande and Thombre (2009) and Nataraju (2012) were contradictory to the present study results.

\section{Family size}

The Table 1 showed that in the study area majority (54.44\%) of the respondents was having medium (5-8 members) family size 
followed by small (31.12\%) and large $(14.44 \%)$ family size. The findings of Nataraju (2012) supported the present results. Whereas, The findings of Gour (2002), Wadear et al., (2003), Khin Mar Oo (2005), Arora et al., (2006), Mande and Thombre (2009) and Satyanarayan and Jagadeeswary (2010) were contradictory.

\section{Land holding}

The Table 1 revealed that more marginal farmers $(52.77 \%)$ followed by small farmers $(28.33 \%)$, semi-medium farmers $(14.44 \%)$, medium (4.4\%) and no large farmers were found in the study area. The findings of Mande and Thombre (2009) and Nataraju (2012) were contradictory to the present study results.

\section{Herd size}

Herd size indicated the number of animals reared by the respondents at the time of investigation. The classification of respondents with respect to indigenous cattle, crossbreed cattle, buffalo according to different land categories are presented in Table 1. It was calculated that 47.77 per cent respondents were having 4 to 6 animals in their herd, whereas 29.46 per cent respondents reared up to 3 animals/household in the study area and in case of large farmers 22.77 per cent were having large herd size (>6). The findings of Gour (2002), Wadear et al., (2003) were contradictory to the present study results.

\section{Experience in dairying and sericulture}

It could be inferred from the Table 1 that majority $(54.44 \%)$ of the respondents belonged to low level of experience in dairying and sericulture, followed by medium experience in dairying (37.23\%) and high level of experience $(8.33 \%)$. The observations made by Fami (2000) are in line with the present study. But according to Bhagyalaxmi et al., (2003), Khin Mar Oo (2005) and Nataraju (2012) it contradicted the findings of the present study.

\section{Annual income}

The respondents were classified in to three categories i.e. low, medium and high annual gross income by applying cumulative square root frequency method and results were presented in Table 1. A cursory look on results revealed that 52.22 per cent respondents belonged to medium category ( 1 lakh to 2 lakh) of annual gross income. However, the average annual income of the respondent family was ₹ 2,01,806 in the study area. The findings of the present study were in conformity with the finding of Khin Mar Oo (2005); whereas, it was against the finding of Mande and Thombre (2009), Satyanarayan and Jagadeeswary (2010) and Nataraju (2012).

\section{Milk production}

Bird's eye view of the Table 1 indicated that on an overall basis 53.88 per cent of the farmers fell in medium category of milk production (5.47 to 12.26 litres/day) followed by 28.35 per cent as low milk yielders with less than 7litres/day. The findings of the present study were in conformity with the finding of Tanwar et al., (2015).

\section{Social participation}

Majority of the respondents had low participation which was about 60.00 per cent followed by medium participation about 26.66 per cent and high participation accounted 13.34 per cent. The findings of the present study were in line with the finding of Kalakaravar (1999), Vanitha (2002), Anitha (2004). 
Table.1 Socio-economic profile of the farmers practicing sericulture based dairy farming

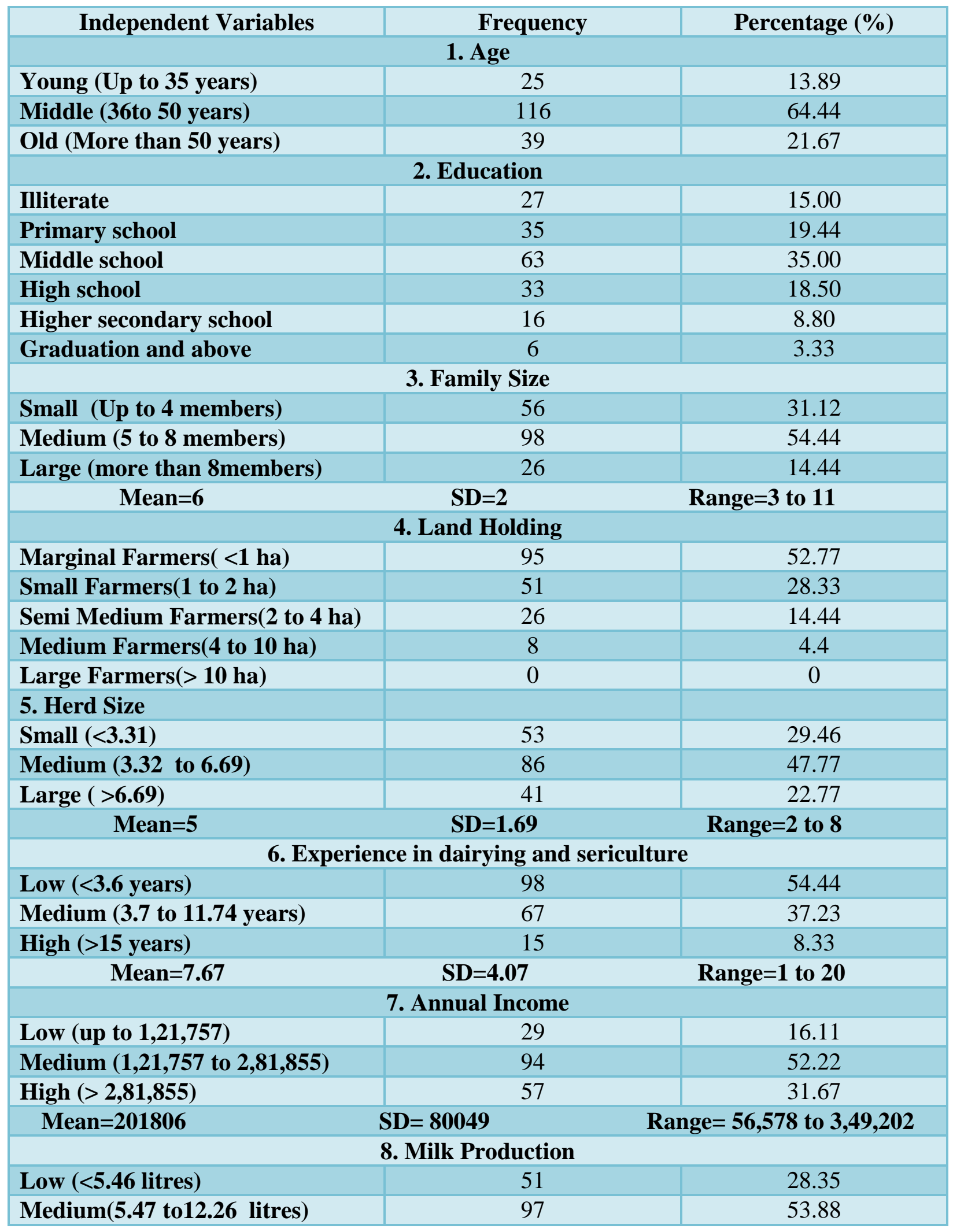




\begin{tabular}{|c|c|c|}
\hline High (> 12.26 litres) & 32 & 17.77 \\
\hline Mean=8.86 litres & $\mathrm{SD}=3.40$ & Range $=3$ to 15 \\
\hline \multicolumn{3}{|c|}{ 9. Social Participation } \\
\hline Low $(<1.85)$ & 108 & 60.00 \\
\hline Medium (1.86 to 5.05) & 48 & 26.66 \\
\hline $\operatorname{High}(>5.05)$ & 24 & 13.34 \\
\hline Mean $=3.45$ & $\mathrm{SD}=1.6$ & Range $=1$ to 7 \\
\hline \multicolumn{3}{|c|}{ 10. Extension contact } \\
\hline No contact & 10 & 5.55 \\
\hline Low (1 to 1.52) & 81 & 45.00 \\
\hline Medium(1.53 to 4.28 ) & 56 & 31.12 \\
\hline High $(>4.28)$ & 33 & 18.33 \\
\hline Mean $=2.9$ & $\mathrm{SD}=1.38$ & Range $=0$ to 4 \\
\hline \multicolumn{3}{|c|}{ 11. Mass Media Exposure } \\
\hline Low $(<8.55)$ & 27 & 15.00 \\
\hline Medium (8.56 to 12.91 ) & 46 & 25.56 \\
\hline High (> 12.91) & 107 & 59.44 \\
\hline Mean $=10.78$ & $\mathrm{SD}=2.13$ & Range $=6$ to 14 \\
\hline
\end{tabular}

$\mathbf{S D}=$ Standard Deviation

\section{Extension contact}

It could be seen from the Table 1 that majority $(50.55 \%)$ of the respondents belonged to low level of contact with extension personnel, followed by medium level $(31.12 \%)$ and high level of contact $(18.33 \%)$ respectively. The findings of the present study were in agreement with the finding of Dhamodaran and Vasanth Kumar (2001).

\section{Mass media exposure}

The classification of the respondents with respect to mass media exposure presented in Table 1 enunciated that maximum number of respondents belonged to maximum level (59.44\%) exposure followed by medium level $(25.56 \%)$ and low level (15.00\%). The findings of the present study were in corroboration with the finding of Nataraju (2012).
The overall assessment of the socio-economic profile of farmers practicing sericulture based dairy farming indicated that, Karnataka state was having better opportunity and potentiality to prosper in the field of sericulture based dairy farming. A large number of sericulture based dairy farmers in the study area were middle aged and completed middle and high schooling level education and therefore had better potential to adopt scientific package and practices, majority were falling under medium annual income category.

Nearly half of respondents were having herd size of 4 to 6 animals; and more than half of the farmers fell in medium category of milk production. Majority of the respondents had high level of mass media exposure and had less social participation. Even the experience in dairy and sericulture among the farmers was low. The present study also suggest that there is strong need to sensitize and train the farmer and other stakeholders about the 
scientific sericulture based dairy farming through adequate extension, policy and financial support for holistic development of sericulture and dairy based integrated farming in Karnataka state.

\section{Acknowledgement}

Authors are thankful to the ICAR-NDRI for providing financial assistance in terms of institutional fellowship and also thankful to Director, ICAR-NDRI, Karnal, and Head, Division of Dairy Extension for providing the necessary facilities for carrying out the research work.

\section{References}

Anitha, B. (2004). A study on entrepreneurial behaviour and market participation of farm women in Bangalore rural district of Karnataka (Doctoral dissertation, University of Agricultural Sciences, GKVK).

Arora, A. S., Kumar, A., Bardhan, D. and Dabas, Y. P. S. (2006). Socioeconomic and communication variables associated with level of knowledge and degree of adoption of improved dairy husbandry practices in US Nagar district of Uttaranchal. Indian Journal of Dairy Science, 59(5), 337-343.

Bhagyalaxmi, K., Rao, G.K.V. and Reddy, S.M. (2003). Profile of the rural women micro entrepreneurs. Journal of Research 31(4): 51-54

Chauhan, D. S., Kamble, V. J., Padghan, P. V., Sawant, R. C. and Kamble, R. R. (2004). Impact of farmers' status on milk production in tribal area of Kinwat Tahasil (Marathwada Region). Indian Journal of Animal Research, 38(2): 137-140.

DAHD\&F (2018-2019). Department of Animal Husbandry, Dairy and
Fisheries

http://www.dahd.nic.in/about-

us/divisions/cattle-and-dairy-

development. Retrieved on 16 January 2020.

Dhamodaran, T. and Vasanth Kumar, J. (2001). Relationship between selected characteristics of registered sugarcane growers and their extent of adoption of improved sugarcane cultivation practices. J. Extn. Edu. 12(2): 3138 3143.

Fami, S. H. (2000). Participation of rural women in mixed farming in Iran. Ph.D. Thesis, University of Agricultural Sciences, Bangalore.

Gaur, A. K. (2002). Factors influencing adoption of some improved animal husbandry practices of dairy in Anand and Vadodara district of Gujarat state (Doctoral dissertation, Ph. D. Thesis).

Kalakaravar, G. (1999). Role performance and training needs identification of panchayat women members. M. Sc. Thesis, University Agricultural Sciences, Dharwad. Karnataka (India).

Khin Mar Oo. (2005). Knowledge and adoption of improved dairy management practices by women dairy farmers in Dharwad district (Doctoral dissertation, UAS, Dharwad).

Komala, C. N. (2002). Risk Efficient Farming System for Sustainable Agriculture Models for Kolar District of Karnataka, M.Sc. thesis Submitted to the University of Agricultural Sciences, Bangalore, India, 161.

Kumar, S. (2009). A Study on technological gap in adoption of the improved soybean cultivation practices (Doctoral dissertation, UAS, Dharwad)

Mande, J. V. and Thombre, B. M. (2009). Adoption of cattle rearing practices by dairy cattle owners in Latur district. 
Journal of Dairying, Foods and Home Sciences, 28(3and4), 176-180.

Nataraju, B. (2012). Study on Participation of Women in Dairy Farming in Chickmagalur District (Doctoral dissertation, University of Agricultural Sciences GKVK, Bangalore).

NDDB (2018-19). Annual Report 2017-18. National Dairy Development Board, India.

NSSO (2011-2012). National Sample Survey Office, Ministry of Statistics and Program Implementation. $68^{\text {th }}$ round 2011-2012). www.indianstatistics.org. Retrieved on 17 January 2020

Satyanarayan, K. and Jagadeeswary, V. (2010). A study on knowledge and adoption behaviour of livestock farmers. Indian Journal of Animal
Research, 44(2), 100-106.

Tanwar, P. S., Kumar, Y. and Aulakh, G. S. (2015). Impact of dairy cooperatives on milk production, income and employment generation in Semi-Arid Rajasthan. International Journal in Management and Social Science, 3(3), 477-487.

Vanitha, C. (2002). Awareness and impact of SGSY on women beneficiaries and their attitude towards the programme. M.Sc. (Agri.) Thesis, University of Agricultural Sciences, Bangalore.

Wadear, P. R., Kiresur, V. R. and Gaddi, G. M. (2003). Human labour absorption in dairy farming in Karnataka-An economic analysis. Rural India, 66(12), 243-247.

\section{How to cite this article:}

Girish, C. E., K. S. Kadian, B. S. Meena and Kalyan Mandi. 2020. Socio-Economic Profile of Farmers in Sericulture Based Dairy Farming System in Karnataka State, India. Int.J.Curr.Microbiol.App.Sci. 9(04): 2071-2078. doi: https://doi.org/10.20546/ijcmas.2020.904.248 